\title{
Stigma and social support in substance abuse: Implications for mental health and well-being
}

\author{
Michèle D. Birtel, (a), Lisa Wood (b,c), Nancy J. Kempac, (c) \\ a School of Psychology, University of Surrey, Guildford GU2 7XH, UK \\ b Inpatient and Acute Directorate, North East London NHS Foundation Trust, Goodmayes \\ Hospital, Barley Lane, Ilford IG3 8XJ, UK \\ c School of Psychological Sciences, University of Manchester, Manchester M13 9PL, UK
}

\begin{abstract}
Individuals with substance abuse may suffer from severe public and internalized stigma. Little is known about how social support can reduce stigma and improve mental health and well-being for them. This research examined how perceived stigma influences individuals in treatment for substance abuse, and whether internalized stigma and shame are mechanisms which link social support with better mental health and wellbeing. Sixty-four participants in treatment for substance abuse (alcohol, drugs), aged between 18 and 64, completed an online survey measuring perceived stigma, internalized stigma, shame, perceived social support, and mental health and well-being (self-esteem, depression and anxiety, sleep). We found that perceived stigma was associated with lower self-esteem, higher depression and anxiety, and poorer sleep. Furthermore, perceived social support followed the opposite pattern, and was associated with higher self-esteem, lower depression and anxiety, and better sleep. The effects of perceived stigma and of perceived social support on our outcome measures were mediated by internalized stigma and by internalized shame. Helping individuals with substance abuse to utilize their social support may be fruitful for combatting the negative impact of internalized stigma and shame on mental health and well-being.
\end{abstract}

\section{Introduction}

Substance abuse is a widespread problem that has enormous consequences. Individuals experiencing substance abuse face a double challenge in society. Firstly, they have to manage their primary symptoms of their serious condition and seek treatment. Secondly, they face severe stigma attached to their diagnosis which impacts 
further upon their physical and mental health (Schomerus et al., 2011a, 2011b; Parcesepe and Cabassa, 2013; Barry et al., 2014). In addition, individuals with substance abuse suffer indirectly through economic and social disadvantages, even when receiving treatment (Link et al., 1997; Klingemann and Gmel, 2001; Rehm et al., 2009; Van Boekelet al., 2013a, 2013b). Social support is a crucial coping mechanism in physical and mental illness (Thoits, 2011). The present research examined whether social support is associated with reduced internalized stigma and shame in individuals in treatment for substance abuse, and in turn with enhanced mental health and well-being.

\subsection{Stigma of substance abuse}

At an individual level, mental health stigma is a multifaceted construct and can be considered as three separate but correlated constructs: experienced, perceived, and internalized stigma. Experienced stigma can be defined as overt discrimination towards a stigmatized person, perceived stigma as the way the stigmatized individual believes the public perceives them, and internalized stigma as the self-application of stigmatizing beliefs (Corrigan and Watson, 2002; Van Brakel, 2006; LeBel, 2008; Brohan et al., 2010). These constructs also apply to individuals with substance abuse, especially those in treatment (Luoma et al., 2007). Stigmatizing attitudes about substance abuse are widely held by the general public (Crisp et al., 2000; Barry et al., 2014). Public stigma towards drug addiction is more severe compared to stigma towards other mental illnesses such as depression (Barry et al., 2014), for example, in the US individuals with substance abuse are judged as violent and dangerous (Pescosolido et al., 1999; Martin et al., 2000). Furthermore, Americans reported higher social distance towards individuals with substance abuse in private life (socializing, relationships) and work life, and greater willingness to discriminate against them in terms of employment, housing, and governmental policy (Pescosolido et al., 1999; Parcesepe and Cabassa, 2013; Barry et al., 2014). Similar attitudes are reported in other countries like the UK. A large proportion of the UK population (58-78\%) believes that individuals with alcohol and drug addiction are dangerous, unpredictable, hard to talk to, and have themselves to blame (Crisp et al., 2000). Furthermore, a systematic review of 28 studies (Van Boekel et al., 
$2013 b$ ) indicated that it is not only the public who holds negative attitudes towards individuals with substance abuse, but also health professionals. This negatively impacts treatment delivery and outcome. Not only attitudes, but also discrimination is particularly severe for individuals with substance abuse (Schomerus et al., 2011b). These experiences include reduced opportunities in relation to education, employment and housing, poorer relationships, and reduced quality of life in general (Link, 1989; Page, 1996; Penn and Martin, 1998; Corrigan and Watson, 2002; Luoma et al., 2007). Stigma can be a stressor. According to the modified labeling theory, a label through entering treatment can negatively affect health through the stigma associated with the label (Link et al., 1989; Link and Phelan, 2013). Stigmatization occurs when a person possesses a social identity that is devalued (Crocker et al., 1998). Having a substance abuse disorder can be considered as a devalued social identity, and the stigma related to this identity can be perceived as a threat. In their stigmainduced identity threat model, Major and O'Brien (2005) propose that identity threat can negatively impact health. Belonging to a stigmatized group (e.g., group of substance abusers) can lead to affective, physiological, cognitive, and behavioral stress reactions (Blascovich et al., 2001), and result in poorer mental and physical health, such as depression, anxiety, and poorer sleep (Major and O'Brien, 2005; Pascoe and Smart Richman, 2009; Williams and Mohammed, 2009; Beatty et al., 2011; Schomerus et al., 2011a). This is caused by individuals with substance abuse becoming aware of the public's stigmatizing attitudes, agreeing with the stereotypes, and responding with low self-esteem, feelings of shame and blame, social distance, and failure to seek help (Corrigan and Penn, 1999; Corrigan and Watson, 2002; Luoma et al., 2007; Schomerus et al., 2011a).

In addition to internalizing stigma, shame can be internalized as well (Cook, 1987). Shame is a self-conscious emotion and refers to the negative affects and cognitions a person has about their personal attributes, personality characteristics or behaviors (Gilbert, 2000). Shame has been associated with substance abuse, the stigma linked to it, as well as depression and anxiety (Gilbert, 2000; Wiechelt and Sales, 2001; Luoma et al., 2008). While perceived stigma acts as a stressor to an individual's social identity and is linked to low selfesteem, depression and anxiety, social support may improve 
mental health and well-being in individuals with substance abuse by reducing the internalization of public views, for example in terms of lower internalized stigma and shame.

\subsection{Social support}

In general, individuals have the fundamental need to be accepted and approved by the social groups they want to belong to (Baumeister and Leary, 1995). Social rank theory (Gilbert, 2000) proposes that a person who possesses a trait that others disapprove of (e.g., in our case substance abuse) will perceive themselves as inferior to others (of low social ranking). This is an extremely threatening experience, and low social rank is associated with shame as well as a variety of psychopathologies, including depression and anxiety (Birchwood et al., 2000; Gilbert, 2000; Major and O'Brien, 2005). Further evidence for the role of interpersonal relationships for people's health comes from studies examining the effects of social exclusion. Being excluded or rejected by other people can lead to lower self-esteem, depression, anxiety, and neurological responses associated with physical pain (Williams anD Zadro, 2001; Eisenberger et al., 2003; Zadro et al., 2004).

Significant others can be stigmatizing or a source of social support (Mickelson, 2001). There is some evidence that close others who find out about someone's treatment of substance abuse are not very supportive (Luoma et al., 2007; Van Boekel et al., 2016). Individuals in treatment for substance abuse experience the greatest amount of stigma by close significant others (family, partner, friends) (Van Boekel et al., 2016). Individuals with substance abuse are at risk of being marginalized, with stigma enhancing social exclusion in people who need the social support most (Room, 2005).

Previous research has consistently found a positive relationship between social support and well-being (for an overview see Thoits, 2011). Social support refers to the support by significant others within one's social network (e.g., family members, friends - the structural aspect) and can fulfil several functions including emotional, informational, and instrumental support, although experientially similar others (e.g., peer support groups) may also be able to provide such support (Thoits, 2011). Firstly, 
during stressful times, social support shields the harmful impact of stress on physical and mental health. Secondly, social support, for example being integrated in a social network, motivates people to take better care of themselves (Cohen and Wills, 1985). Perceived social support can protect people from negative consequences of stress on physical and mental health, and provide people with stronger coping mechanisms (Cohen and Willis, 1985; Cohen et al., 1986; Baumeister and Leary, 1995; Uchino, 2006). Social support seems crucial for individuals with substance abuse to not only improve the primary symptoms and physical health (e.g., decreased likelihood of relapse, Ellis et al., 2004), but also to enhance their own coping strategies and buffer against stigma and its negative consequences.

Previous research suggests that social support and internalized stigma are predictors of mental health (e.g., depression) in individuals experiencing stigma, for example HIV (Simbayi et al., 2007; Li et al., 2009) and sexual orientation (Beals et al., 2009). Stigma can have a negative effect on social support, but social support can also positively influence stigma: While previous research has suggested that perceived social support can be a mediator between perceived stigma and wellbeing, for example in depression (Mickelson, 2001), the link between stigma and perceived social support may also work in the other direction, from social support to stigma, when considering internalized instead of perceived stigma. For example, internalized stigma has been shown to mediate the relationship between social support and depression in HIV (Vyavaharkar et al., 2010). Furthermore, a poor social network has shown to increase internalized stigma in schizophrenia (Sibitz et al., 2011), and social support predicted stigma in mental illness one year after diagnosis (Mueller et al., 2006). If individuals with substance abuse perceive close others (e.g., family or friends) to be supportive, they may internalize the public views less, and this lower internalized stigma (and lower internalized shame) is then associated with higher well-being.

Perceived support has shown to be a better predictor of mental health than objectively measured social support (e.g., Zimet et al., 1988; Thoits, 2011; Nguyen et al., 2016). Therefore, in our study, social support was measured by assessing subjective 
perceptions of socialsupport from three significant sources (family, friends, significant other).

\subsection{The current study}

While previous research has established the various facets of stigma and its existence in substance abuse (e.g., Link et al., 2004; Luoma et al., 2007), little attention has been paid to internalized stigma and shame in individuals with substance abuse (Schomerus et al., 2011a). While there is research showing that perceived stigma in mental illness leads to lower self-esteem (Link et al., 2001; Corrigan et al., 2006), and higher depression (Pascoe and Smart Richman, 2009), this research also considers sleep. Sleep has not only been linked to mental health but also to having a stigmatized social identity, for example ethnic minority group members who experienced more discrimination also reported poorer sleep (Thomas et al., 2006; Beatty et al., 2011). Furthermore, previous research suggests that shame is associated with stigma (for example in depression, Gilbert, 2000), and that internalized stigma and shame are associated with poorer mental health (Gilbert, 2000; Corrigan et al., 2006; Livingston and Boyd, 2010).

This study examined whether perceived stigma was associated with poorer mental health and well-being in individuals in treatment for substance abuse through internalized stigma and shame. Based on the review of the current literature, we tested the following two hypotheses for perceived stigma:

- H1a: Perceived stigma of substance abuse is associated with higher internalized stigma, higher internalized shame, and lower mental health and well-being (lower self-esteem, higher depression and anxiety, and poorer sleep).

- H1b: The negative effects of perceived stigma on mental health and well-being are mediated by internalized stigma and by internalized shame.

Furthermore, little attention has been paid to social support and stigma in substance abuse. Significant others can be stigmatizing (Luoma et al., 2007; Van Boekel et al., 2016). On the other hand, social support, if utilized, is a vital coping mechanism (Cohen and Wills, 1985), and is linked to better health and well-being (Gilbert, 2000; 
Thoits, 2011). Previous research shows that social support predicts stigma (Mueller et al., 2006; Sibitz et al., 2011), that social support and internalized stigma predict mental health (Simbayi et al., 2007; Beals et al., 2009; Li et al., 2009), and that internalized stigma mediates the relationship between social support and mental health (Vyavaharkar et al., 2010) in stigmatized individuals such as HIV and schizophrenia. This study examined whether perceived social support in substance abuse was linked to greater mental health and well-being, and whether lower internalized stigma and shame were the mechanisms. Based on the review of the current literature, we tested the following two hypotheses for perceived social support:

- H2a: Perceived social support is associated with lower internalized stigma, lower internalized shame, and better mental health and wellbeing.

- H2b: The positive effects of perceived social support on mental health and well-being are mediated by internalized stigma and by internalized shame.

In summary, we propose the following mediational models: Perceived stigma is predicted to have a negative effect, and perceived social support is predicted to have a positive effect on mental health and well-being in individuals in treatment for substance abuse. Furthermore, internalized stigma and internalized shame are predicted to mediate the relationships between perceived stigma and mental health/well-being, and perceived social support and mental health/well-being.

\section{Method}

\subsection{Participants}

Sixty-four participants were recruited from various (non-NHS) UK substance abuse rehabilitation sites, charities, as well as alcohol and drug recovery networks (27 female, 37 male), aged between 18 and 64 years $(M=32.28, S D=10.34)$ to take part in an online study. The sample size required to detect a medium effect for both a and $\beta$ paths using the bias-corrected bootstrap test of mediation with a power of 0.8 is $N=71$ (Fritz and MacKinnon, 2007). This is only slightly over our sample size, however, a number of studies have used similar sample sizes for the conduction of mediation 
analysis in clinical populations $(n=52$, Wood and Irons, 2016; $n=60$, Hasson-Ohayon et al., 2012; $n=80$, Vass et al., 2015). The inclusion criteria were (a) 18 years of age or older, (b) diagnosis of alcohol and/or drug addiction, (c) fluent speaker of English language, and (d) capacity to provide informed consent to the study. Diagnosis was determined by the fact that individuals received treatment for their condition at the time of study participation (alcohol: $N=21$, drugs: $N=21$, both: $N=22$ ). Fifty-eight participants were Caucasian, 3 were from a mixed ethnic background, 2 were Hispanic, and 1 was Jewish. When asked about religious affiliation, 40 participants identified as Atheist or had no religion, 15 as Christian, 6 as Agnostic, 2 as Buddhist, and 1 as Jewish.

\subsection{Procedure}

Participants were contacted via staff members of the substance abuse treatment sites who received emails with information about the study, posters, flyers, and the link to the online survey. After providing informed consent, participants completed the demographics and outcome measures. The research was conducted in accordance with the ethical principles of the Declaration of Helsinki (World Medical Association, 2013) and the UK Medical Research Council's Guidelines for Good Clinical Practice (Medical Research Council, 2012), and received ethical approval by the local institutional research and ethics committee.

\subsection{Measures}

\subsubsection{Predictor variables}

2.3.1.1. Perceived stigma. Perceived stigma associated with substance abuse was measured using the 8-item Perceived Stigma of Substance Abuse Scale (PSAS; Luoma et al., 2010), on a 4-point Likert scale ranging from $1=$ strongly disagree to $4=$ strongly agree, for example "Most people think less of a person who has been in treatment for substance use" and "Most people believe that someone who has been treated for substance use is just as trustworthy as the average citizen" (reverse). Items were recoded such that higher scores represented higher perceived stigma. A composite 
perceived stigma score was computed by the mean of these items (Cronbach's $a=0.84$, with 1 being low, 2.5 being moderate, 4 being high levels).

2.3.1.2. Perceived social support. Perceived social support was measured using the Multidimensional Scale of Perceived Social Support (MSPSS; Zimet et al., 1988). Participants indicated their social support from three different sources, i.e., family, friends, and significant other, on 12 items on a 7-point Likert scale ranging from 1= very strongly disagree to $7=$ very strongly agree, for example "My family really tries to help me", "I can talk about my problems with my friends", and "There is a special person in my life who cares about my feelings". A composite social support score was computed by the mean of these items, with higher scores representing greater perceived social support (Cronbach's $a=0.93$, with 1 being low, 4 being moderate, 7 being high levels).

\subsubsection{Mediator variables}

2.3.2.1. Internalized stigma. To measure internalized stigma of substance abuse, the Internalized Stigma of Mental Illness scale (ISMI; Ritsher et al., 2003) was adapted by changing the term 'mental illness' to 'substance abuse'. Participants were asked to complete the 29 items on a 4-point Likert-scale ranging from 1= strongly disagree to $4=$ strongly agree, for example "I am disappointed in myself for having a substance abuse problem", “Stereotypes about substance abusers apply to me”, and "I don't talk about myself much because I don't want to burden others with my substance abuse problem". Items were recoded such that higher scores represented higher stigma. A composite stigma score was computed by the mean of these items (Cronbach's $\alpha=0.94$, with 1 being low, 2.5 being moderate, 4 being high levels).

\subsubsection{Internalized shame. Participants were asked to complete the 30 -item Internalized} Shame Scale (ISS; Cook, 1987) on a 5-point Likert scale ranging from $1=$ never to $5=$ almost always, for example "I feel like I am never quite good enough", "I feel insecure about other opinions of me", and "Sometimes I feel no bigger than a pea". A composite internalized shame score was computed by the mean of the 24 shame-related items 
and omitting the 6 self-esteem related items, with higher scores representing greater internalized shame (Cronbach's a=0.96, with 1 being low, 3 being moderate, 5 being high levels).

\subsubsection{Criterion variables}

2.3.3.1. Self-esteem. Participants were asked to complete the 10-item Rosenberg's SelfEsteem Scale (RSE; Rosenberg, 1965) on a 5-point Likert scale ranging from $0=$ strongly disagree to $4=$ strongly agree, for example "On the whole, I am satisfied with myself" and "I take a positive attitude toward myself". Items were recoded such that higher scores represented greater self-esteem. A composite self-esteem score was computed by the mean of these items (Cronbach's a=0.92, with 0 being low, 2 being moderate, 4 being high levels).

\subsubsection{Depression and anxiety. The 4-item Patient Health Questionnaire (PHQ-4;} Kroenke et al., 2009) was used to measure depression and anxiety on a 4-point Likert scale ranging from $0=$ not at all to $3=$ nearly every day, indicating the frequency of depressive and anxious symptoms over the previous two weeks, for example "Feeling nervous, anxious or on edge" and "Feeling down, depressed or hopeless". A composite depression and anxiety score was computed by the mean of these items, with higher scores representing higher depression and anxiety (Cronbach's $a=0.86$, with 0 being low, 1.5 being moderate, 3 being high levels).

2.3.3.3. Sleep. Sleep quality was measured using the Bergen Insomnia Scale (BIS; Pallesen et al., 2008). Participants were asked to respond to six items relating to sleep and tiredness on a 7 -point Likert scale ranging from $1=$ no days to $7=$ every day, referring to the number of days per week, for example "During the past month, how many days a week have you felt that you have not had enough rest after waking up?". A composite sleep score was computed by the mean of these items, with lower scores representing better sleep (Cronbach's $a=0.89$, with 1 being high, 4 being moderate, 7 being low levels). 


\subsection{Statistical analyses}

All analyses were carried out using SPSS version 22. Data were screened for normality. Z-standardized skewness and kurtosis values suggest that data are normally distributed (cut-off value $\mathrm{z}=1.96$ ), apart from the skewness scores for ISMI $(z s k e w=2.28)$, and MSPSS (zskew=2.64). Given the only small deviations from normality and the fact that a Spearman correlation analysis yielded similar results, a Pearson correlation analysis was calculated to examine the relationships between our measures. Multicollinearity was not a problem, all Tolerance values were $>0.02$ (Menard, 1995), and all VIF values were <10 (Bowerman and O'Connell, 1990; Myers, 1990). To test our meditational hypotheses, bootstrapping analyses (1000 subsamples, 95\% bias-corrected and accelerated confidence interval) were conducted by estimating the indirect effect using the PROCESS macro provided by Hayes (2013). ${ }^{1}$ The bootstrapping method (instead of the Sobel test, Baron and Kenny, 1986) to test mediation is recommended for small sample sizes (Preacher and Hayes, 2008b).

\section{Results}

Means and standard deviations for all measures can be found in Table 1. Participants in our sample experienced moderate to high levels of perceived stigma $(M=2.94)$, social support $(M=5.06)$ and sleep quality $(M=3.20)$; moderate levels of shame (M=2.97) and self-esteem (M=2.35); and low to moderate levels of internalized stigma $(M=2.00)$, and depression and anxiety $(M=1.06)$.

\subsection{Correlations}

To examine the relationships between perceived stigma (and perceived social support, respectively) and our outcome measures, a Pearson correlation analysis was calculated (see Table 1). Perceived stigma towards substance abuse was significantly

\footnotetext{
1 The major flaw of the Sobel test (Baron and Kenny, 1986) is that it requires the assumption of normality of the sampling distribution of the indirect effect. However, finite or small samples are rarely normally distributed. Therefore, bootstrapping, a nonparametric resampling procedure, is recommended over the Sobel test as it makes no assumptions about the shape of the sampling distribution of the indirect effect (Preacher and Hayes, 2008a).
} 
associated with higher levels of internalized stigma and shame, lower self-esteem, higher depression and anxiety, and poorer sleep. For perceived social support, the correlation analysis revealed the opposite pattern. The greater individuals with substance abuse perceived their social support, the lower were their internalized stigma of substance abuse and their internalized shame. Moreover, perceived social support was significantly associated with higher self-esteem, and lower depression and anxiety, and better sleep.

\subsection{Mediation models}

\subsubsection{Perceived stigma}

We computed mediation analyses to assess whether the effect of perceived stigma on mental health and well-being (self-esteem, depression and anxiety, sleep) was mediated by variation in internalized stigma. Results can be found in Table 2. As hypothesized, perceived stigma significantly predicted self-esteem, depression and anxiety, and sleep, $\mathrm{p}<0.05$ for all total effects. Higher levels of perceived stigma were associated with lower self-esteem, higher depression and anxiety, and poorer sleep. There were significant indirect effects of perceived stigma on self-esteem, depression and anxiety, and sleep, through internalized stigma. As hypothesized, the relationships between perceived stigma (predictor) and self-esteem, depression and anxiety, and sleep (outcome variables) were mediated by internalized stigma. Higher perceived stigma was associated with higher internalized stigma, and in return with lower self-esteem, higher depression and anxiety, and poorer sleep. The mediation analyses yielded large effect sizes (Preacher and Kelley, 2011), Kappa-squared ranged from 0.20 to 0.41 .

We then computed similar mediation analyses to assess whether the effect of perceived stigma on mental health and well-being was mediated by variation in internalized shame. Results can be found in Table 3. As hypothesized, perceived stigma significantly predicted selfesteem, depression and anxiety, and sleep, $\mathrm{p}<0.05$ for all total effects. There were significant indirect effects of perceived stigma on selfesteem, depression and anxiety, and sleep, through internalized shame. 
Table 1

Pearson correlation matrix, means, and standard deviations for all measures.

\begin{tabular}{|l|l|l|l|l|l|l|l|l|l|}
\hline Measure & 1 & 2 & 3 & 4 & 5 & 6 & $\mathrm{n}$ & $\mathrm{M}$ & $\mathrm{SD}$ \\
\hline $\begin{array}{l}\text { 1. Perceived } \\
\text { Stigma }\end{array}$ & - & & & & & & 64 & 2.94 & 0.47 \\
\hline $\begin{array}{l}\text { 2. Perceived } \\
\text { Social } \\
\text { Support }\end{array}$ & $-0.56^{* *}$ & - & & & & & 64 & 5.06 & 1.49 \\
\hline $\begin{array}{l}\text { 3. } \\
\text { Internalized } \\
\text { Stigma }\end{array}$ & $0.64^{* *}$ & $-0.73^{* *}$ & - & & & & 64 & 2.00 & 0.59 \\
\hline $\begin{array}{l}\text { 4. } \\
\text { Internalized } \\
\text { Shame }\end{array}$ & $0.51^{* *}$ & $-0.59^{* *}$ & $0.73^{* *}$ & - & & & 64 & 2.97 & 0.90 \\
\hline $\begin{array}{l}\text { 5. Self- } \\
\text { Esteem }\end{array}$ & $-0.47^{* *}$ & $0.68^{* *}$ & $-0.71^{* *}$ & $-0.83^{* *}$ & - & & 64 & 2.35 & 0.99 \\
\hline 6. PHQ-4 & $0.41^{* *}$ & $-0.38^{* *}$ & $0.48^{* *}$ & $0.62^{* *}$ & $-0.57^{* *}$ & - & 64 & 1.06 & 0.89 \\
\hline 7. Sleep & $0.42^{* *}$ & $-0.38^{* *}$ & $0.57^{* *}$ & $0.59^{* *}$ & $-0.52^{* *}$ & $0.58^{* *}$ & 63 & 3.20 & 1.96 \\
\hline
\end{tabular}

${ }^{* *} \mathrm{p}<0.01$ (two-tailed).

Table 2

Total, direct, and indirect effects of perceived stigma on all dependent variables, mediator: internalized stigma.

\begin{tabular}{|c|c|c|c|c|c|}
\hline & & & & \multicolumn{2}{|c|}{$95 \%$ BCa CI } \\
\hline Dependent variable & $B$ & $S E(B)$ & $p$ & $L L$ & $U L$ \\
\hline \multicolumn{6}{|l|}{ Self-esteem } \\
\hline Total effect & -0.98 & 0.24 & $<0.001$ & - & - \\
\hline Direct effect & -0.03 & 0.25 & 0.897 & - & - \\
\hline Indirect effect & -0.94 & 0.23 & - & -1.44 & -0.56 \\
\hline$\kappa 2$ & 0.41 & 0.08 & - & -0.25 & 0.57 \\
\hline \multicolumn{6}{|c|}{ Depression and anxiety } \\
\hline Total effect & 0.76 & 0.22 & $<0.001$ & - & - \\
\hline Direct effect & 0.32 & 0.27 & 0.244 & - & - \\
\hline Indirect effect & 0.44 & 0.22 & - & 0.06 & 0.94 \\
\hline к2 & 0.20 & 0.10 & - & 0.03 & 0.41 \\
\hline \multicolumn{6}{|l|}{ Sleep } \\
\hline Total effect & 1.71 & 0.48 & $<0.001$ & - & - \\
\hline Direct effect & 0.29 & 0.58 & 0.616 & - & - \\
\hline Indirect effect & 1.42 & 0.39 & - & 0.76 & 2.33 \\
\hline $\mathrm{\kappa} 2$ & 0.29 & 0.07 & - & 0.15 & 0.44 \\
\hline
\end{tabular}

Note. $B=$ unstandardized coefficient, $S E=$ standard error, $p$ reported two-tailed, $95 \% \mathrm{BCa}$ $\mathrm{CI}=95 \%$ bias-corrected and accelerated confidence interval, $L L=$ lower limit, $U L=$ upper limit. 
Table 3

Total, direct, and indirect effects of perceived stigma on all dependent variables, mediator: internalized shame.

\begin{tabular}{|c|c|c|c|c|c|}
\hline & & & & \multicolumn{2}{|c|}{$95 \% \mathrm{BCa} \mathrm{CI}$} \\
\hline Dependent variable & $B$ & $S E(B)$ & $p$ & $L L$ & $U L$ \\
\hline \multicolumn{6}{|l|}{ Self-esteem } \\
\hline Total effect & -0.98 & 0.24 & $<0.001$ & - & - \\
\hline Direct effect & -0.11 & 0.17 & 0.514 & - & - \\
\hline Indirect effect & -0.86 & 0.22 & - & -1.31 & -0.44 \\
\hline к2 & 0.45 & 0.08 & - & 0.26 & 0.59 \\
\hline \multicolumn{6}{|c|}{ Depression and anxiety } \\
\hline Total effect & 0.76 & 0.22 & $<0.001$ & - & - \\
\hline Direct effect & 0.23 & 0.22 & 0.299 & - & - \\
\hline Indirect effect & 0.54 & 0.17 & - & 0.26 & 0.87 \\
\hline $\mathrm{k} 2$ & 0.28 & 0.08 & - & 0.14 & 0.44 \\
\hline \multicolumn{6}{|l|}{ Sleep } \\
\hline Total effect & 1.71 & 0.48 & $<0.001$ & - & - \\
\hline Direct effect & 0.63 & 0.49 & 0.204 & - & - \\
\hline Indirect effect & 1.08 & 0.43 & - & 0.42 & 2.18 \\
\hline к2 & 0.25 & 0.09 & - & 0.10 & 0.46 \\
\hline
\end{tabular}

Note. $\mathrm{B}=$ unstandardized coefficient, $\mathrm{SE}=$ standard error, $\mathrm{p}$ reported two-tailed, $95 \% \mathrm{BCa}$ $\mathrm{CI}=95 \%$ bias-corrected and accelerated confidence interval, $\mathrm{LL}=$ lower limit, $\mathrm{UL}=$ upper limit.

Table 4

Total, direct, and indirect effects of perceived social support on all dependent variables, mediator: internalized stigma.

\begin{tabular}{|l|l|l|l|l|l|}
\hline & & & & \multicolumn{2}{c|}{ 95\% BCa CI } \\
\hline Dependent variable & \multicolumn{1}{|c|}{$B$} & \multicolumn{1}{|c|}{$S E(B)$} & \multicolumn{1}{c|}{$p$} & \multicolumn{2}{c|}{ UL } \\
\hline Self-esteem & & & & & \\
\hline Total effect & 0.45 & 0.06 & $<0.0001$ & - & - \\
\hline Direct effect & 0.23 & 0.17 & 0.007 & - & - \\
\hline Indirect effect & 0.22 & 0.22 & - & 0.08 & 0.43 \\
\hline$\kappa 2$ & 0.32 & 0.08 & - & 0.14 & 0.50 \\
\hline Depression and anxiety & & & & & \\
\hline Total effect & -0.23 & 0.07 & 0.002 & - & - \\
\hline Direct effect & -0.05 & 0.10 & 0.637 & - & - \\
\hline Indirect effect & -0.18 & 0.10 & - & -0.41 & -0.02 \\
\hline к2 & 0.23 & 0.11 & - & 0.03 & 0.46 \\
\hline Sleep & & & & & \\
\hline Total effect & -0.49 & 0.15 & 0.002 & - & - \\
\hline Direct effect & 0.17 & 0.21 & 0.415 & - & - \\
\hline Indirect effect & -0.66 & 0.17 & - & -1.02 & -0.35 \\
\hline$\kappa 2$ & 0.37 & 0.08 & - & 0.20 & 0.52 \\
\hline
\end{tabular}

Note. $\mathrm{B}=$ unstandardized coefficient, $\mathrm{SE}=$ standard error, $\mathrm{p}$ reported two-tailed, $95 \% \mathrm{BCa}$ 
$\mathrm{CI}=95 \%$ bias-corrected and accelerated confidence interval, $\mathrm{LL}=$ lower limit, $\mathrm{UL}=$ upper limit.

As hypothesized, the relationships between perceived stigma (predictor) and selfesteem, depression and anxiety, and sleep (outcome variables) were mediated by internalized shame. Higher perceived stigma was associated with higher internalized shame, and in return with lower self-esteem, higher depression and anxiety, and poorer sleep. The mediation analyses yielded large effect sizes, Kappa-squared ranged from 0.25 to 0.45 .

\subsubsection{Perceived social support}

We computed mediation analyses to assess whether the effect of perceived social support on mental health and well-being was mediated by variation in internalized stigma. Results can be found in Table 4. As hypothesized, perceived social support significantly predicted self-esteem, depression and anxiety, and sleep, $p<0.05$ for all total effects. There were significant indirect effects of perceived social support on selfesteem, depression and anxiety, and sleep, through internalized stigma. As hypothesized, the relationships between perceived social support (predictor) and selfesteem, depression and anxiety, and sleep (outcome variables) were mediated by internalized stigma. Higher perceived social support was associated with lower internalized stigma, and in return with higher self-esteem, lower depression and anxiety, and better sleep (see Fig. 1). The mediation analyses yielded large effect sizes, Kappa-squared ranged from 0.23 to 0.32 .

We then computed similar mediation analyses to assess whether the effect of perceived social support on mental health and well-being was mediated by variation in internalized shame. Results can be found in Table 5. As hypothesized, perceived social support significantly predicted self-esteem, depression and anxiety, and sleep, $p<0.05$ for all total effects. There were significant indirect effects of perceived social support on self-esteem, depression and anxiety, and sleep, through internalized shame. As hypothesized, the relationships between perceived social support (predictor) and self-esteem, depression and anxiety, and sleep (outcome variables) were mediated by internalized shame. Higher perceived social support was associated 
with lower internalized shame, and in return with higher self-esteem, lower depression and anxiety, and better sleep. The mediation analyses yielded large effect sizes, Kappa-squared ranged from 0.30 to 0.44 .

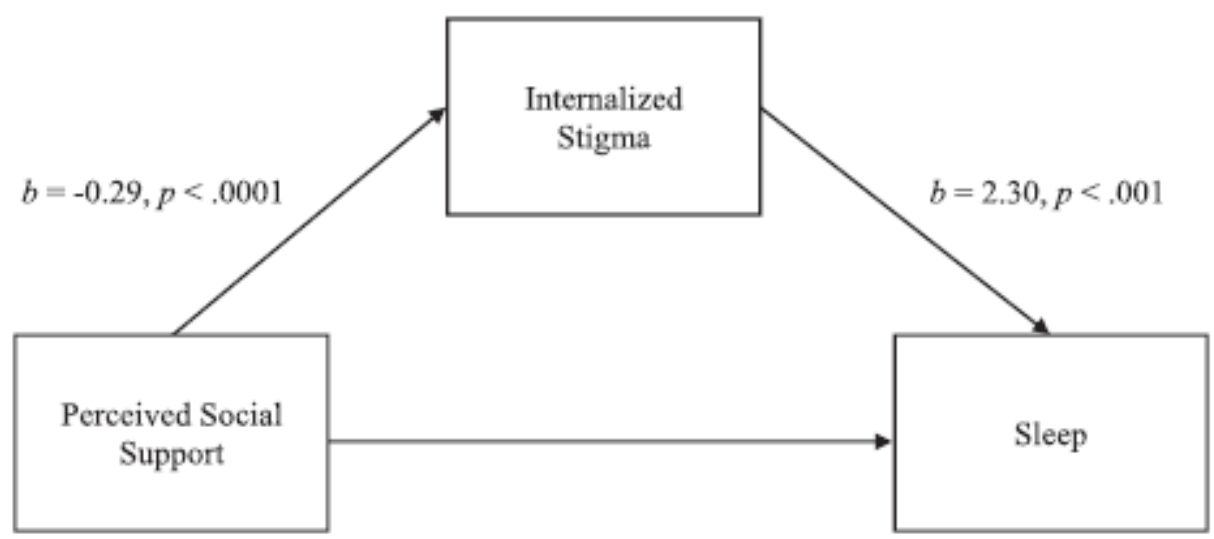

Direct effect, $b=0.17, p=.415$

Indirect effect, $b=-0.66,95 \% \mathrm{CI}[-1.02,-0.35]$

Fig. 1. Internalized stigma as a mediator of the relationship between perceived social support and sleep.

Table 5

Total, direct, and indirect effects of perceived social support on all dependent variables, mediator: internalized shame.

\begin{tabular}{|c|c|c|c|c|c|}
\hline & & & & \multicolumn{2}{|c|}{$95 \%$ BCa CI } \\
\hline Dependent variable & $B$ & $S E(B)$ & $p$ & $L L$ & $U L$ \\
\hline \multicolumn{6}{|l|}{ Self-esteem } \\
\hline Total effect & 0.45 & 0.06 & $<0.0001$ & - & - \\
\hline Direct effect & 0.19 & 0.05 & 0.001 & - & - \\
\hline Indirect effect & 0.26 & 0.05 & - & 0.17 & 0.36 \\
\hline к2 & 0.44 & 0.07 & - & 0.30 & 0.56 \\
\hline \multicolumn{6}{|c|}{ Depression and anxiety } \\
\hline Total effect & -0.23 & 0.07 & 0.002 & - & - \\
\hline Direct effect & -0.01 & 0.07 & 0.848 & - & - \\
\hline Indirect effect & -0.21 & 0.05 & - & -0.32 & -0.13 \\
\hline$\kappa 2$ & 0.33 & 0.07 & - & 0.19 & 0.46 \\
\hline \multicolumn{6}{|l|}{ Sleep } \\
\hline Total effect & -0.49 & 0.15 & 0.002 & - & - \\
\hline Direct effect & -0.05 & 0.21 & 0.775 & - & - \\
\hline Indirect effect & -0.44 & 0.13 & - & -0.72 & -0.20 \\
\hline к2 & 0.30 & 0.09 & - & 0.13 & 0.49 \\
\hline
\end{tabular}

Note. $\mathrm{B}=$ unstandardized coefficient, $\mathrm{SE}=$ standard error, $\mathrm{p}$ reported two-tailed, $95 \% \mathrm{BCa}$ $\mathrm{CI}=95 \%$ bias-corrected and accelerated confidence interval, $\mathrm{LL}=$ lower limit, $\mathrm{UL}=$ upper limit. 


\section{Discussion}

While there is now a wealth of evidence for the stigma towards individuals with substance abuse, we aimed to examine how stigma and social support influences mental health and well-being in individuals in treatment for substance abuse. In particular, we tested whether perceived stigma was associated with greater internalized stigma and shame, and in turn with poorer mental health and well-being. We further tested whether perceived social support could be a coping mechanism, being associated with lower internalized stigma and shame, and in turn with better mental health and well-being. In the following section we summarize the key findings, and explore implications and applications for future research.

Firstly, we found that perceived stigma of substance abuse was associated with lower self-esteem, higher depression and anxiety, and poorer sleep (H1a). While previous research has found that perceived stigma in substance abuse and mental illness is associated with poorer mental health and well-being, e.g., lower self-esteem and more depressive symptoms (Corrigan et al., 2006; Luoma et al., 2007; Pascoe and Smart Richman, 2009), we extend previous findings by showing that perceived stigma is negatively related to other health measures such as sleep. Sleep has been found to be negatively affected by belonging to a stigmatized identity such as an ethnic minority (Thomas et al., 2006; Beatty et al., 2011). We show that sleep is also negatively associated with stigma towards substance abuse.

Furthermore, we give insight into the mechanisms as to why perceived stigma may negatively impact mental health and well-being, i.e., its mediatory relationship with internalized stigma and shame. We found that the effects of perceived stigma on selfesteem, depression and anxiety, and sleep were mediated by internalized shame, and internalized stigma (H1b). These findings are consistent with the literature that shows that perceived stigma is related to internalized stigma and shame in substance abuse (Gilbert, 2000; Luoma et al., 2007), and that perceived and internalized stigma are related to poorer health and well-being (Corrigan et al., 2006; Luoma et al., 2007; Livingston and Boyd, 2010; Schomerus et al., 2011a). We show that those individuals who perceived more stigma towards their diagnosis of substance abuse, were also the 
ones who reported more internalization of the public stigma, which in turn had a negative effect on their health.

Secondly, as hypothesized and in accordance with the current literature, we found that perceived social support was associated with higher self-esteem, lower depression and anxiety, and better sleep (H2a). Previous research has found that social support positively impacts mental and physical health (Thoits, 2011), and has emphasized the crucial role of social support for individuals with ill health (Cohen and Wills, 1985). We extend previous findings to individuals with substance abuse.

Furthermore, no research has looked into the relationship between perceived social support and internalized stigma and shame in individuals with substance abuse yet. We found that, as with perceived stigma, the effects of perceived social support on self-esteem, depression and anxiety, and sleep were mediated by internalized shame, and internalized stigma $(\mathrm{H} 2 \mathrm{~b})$. This is in line with previous research. There is some evidence in the stigma literature that social support and internalized stigma predict depressive symptoms in stigmatized individuals (Simbayi et al., 2007; Beals et al., 2009; Li et al., 2009), and that social support influences stigma (Mueller et al., 2006), with internalized stigma mediating the relationship between social support and depressive symptoms (Vyavaharkar et al., 2010). We extend previous findings to individuals with substance abuse. We show that those individuals who perceived close others to be supportive instead of stigmatizing, were also the ones who reported less internalization of the public stigma, which in turn had a positive effect on their health.

In social and clinical research on attitudes towards individuals with mental illness, the stigma of substance abuse has been examined noticeably less than stigma towards other mental illnesses such as psychosis, despite it being a severely stigmatized mental illness (Schomerus et al., 2011b). This research sheds further light onto the impact of stigma on individuals with substance abuse. As a general pattern, internalized stigma and internalized shame mediated both the negative effects of perceived stigma as well as the positive effects of perceived social support on mental health and well-being.

Being excluded or rejected by other people can lead to lower health and well-being (Williams and Zadro, 2001; Eisenberger et al., 2003; Zadro et al., 2004). Furthermore, 
the majority of individuals with alcohol and drug addiction avoid treatment because they fear the label associated with their diagnosis (Cunningham et al., 1993; Semple et al., 2005). Social support could be beneficial motivating individuals with substance abuse to cope with the negative impact of the stigma attached to their diagnosis, and to seek professional help. Significant others can be a source of stigma or a source of support (Mickelson, 2001). Stigma can reduce a person's social network through social stigma (e.g., exclusion) and internalized stigma (e.g., internalizing social stigma that is anticipated, perceived or experienced). On the other hand, social support can also reduce perceived and internalized stigma. Our results show that perceiving higher social support is associated with lower internalized stigma and shame, suggesting it may be useful to test if interventions which attempt to develop and engage social support could reduce internalized stigma in substance abuse.

While this research has examined social support from three significant sources (family, friends, significant other), further research could focus on support from other sources such as participants' charities or support groups. For example, the new support from groups when they receive treatment (similar others) may serve a different function than relatives (significant others), and therefore have a different impact on stigma and their mental health (Thoits, 2011).

The results are also valuable from a clinical psychotherapeutic perspective. Therapies for treating substance abuse are for example cognitive behavioral therapy (CBT; Beck et al., 2011) and acceptance and commitment therapy (ACT; Hayes, 2004). To date, diagnosis and treatment of internalized stigma in individuals with substance abuse have received little attention. For example, Luoma et al. (2008) developed an ACT for individuals in treatment for substance abuse to reduce their internalized stigma. As individuals with substance abuse experience a high amount of social exclusion, they lose social support as an important coping strategy. Targeting the stigma of substance abuse may not only reduce the negative psychological impact of stigma on people's appraisals of their emotions, cognitions and behaviors, but may also help people to utilize their social support in order to enhance their coping strategies to deal with both their primary illness as well as the stigma attached to it. An important endeavor for future research will be to examine whether individuals in 
treatment for substance abuse who experience greater social support will be more resilient towards stigma and therefore recover more quickly.

There are some limitations to the study. Because the study focused on stigma, a self-selection bias may have led to those participants taking part who experience higher social support. However, looking at the means for perceived and internalized stigma, stigma levels were generally moderate to high, so results with participants who experience lower social support may be even stronger. Furthermore, all variables included were self-report measures so susceptible to social desirability. Future research should examine whether implicit measures of stigma (Fazio et al., 1995; Greenwald and Banaji, 1995) yield similar results to explicit measures of stigma. Third, as our sample was a convenience sample, targeting only non-NHS treatment sites, it may not be representative of individuals with substance abuse and results therefore can only be generalized to those in treatment in non-NHS sites, but not NHS sites. We also do not have information about the specific treatment site participants were coming from, the specific drug they had been taking, or comorbidities. Fourth, as access to individuals with substance abuse was limited, it resulted in a small sample size and cross-sectional data for the mediation analyses. Future research should make use of a larger sample size and a longitudinal design to test whether perceived social support (e.g., at time of diagnosis) and enhanced social support (e.g., via an intervention) could lead to reduced stigma at a later point.

Nevertheless, the results suggest that it may be important to examine the role of social support in stigma towards substance abuse, not only as a stress buffer or mediating variable, but also as a point of intervention to reduce internalized stigma in those individuals who need social support the most.

\section{Conclusion}

Previous research has provided extensive evidence for the severe public and selfstigmatization individuals with substance abuse face. We have shown how perceived stigma of substance abuse is associated with poorer health, i.e., by higher internalization of stigma and shame. More importantly, social support (e.g., from family and friends) was associated with lower internalized stigma and shame, and in 
return with better health in terms of self-esteem, depression and anxiety, and sleep. Our findings suggest the value of helping individuals suffering from substance abuse to utilize social support as a coping strategy to combat the negative impact of internalized stigma and shame on physical and mental health.

\section{Acknowledgment}

We thank three anonymous reviewers for their careful reading of the manuscript, and their valuable comments and suggestions.

\section{References}

Baron, R.M., Kenny, D.A., 1986. The moderator-mediator variable distinction in social psychological research: conceptual, strategic, and statistical considerations. J.

Personal. Soc. Psychol. 51, 1173-1182. http:// dx.doi.org/10.1037//0022-

3514.51.6.1173.

Barry, C.L., McGinty, E.E., Pescosolido, B.A., Goldman, H.H., 2014. Stigma, discrimination, treatment effectiveness, and policy: Public views about drug addiction and mental illness.

Psychiatr. Serv. 65, 1269-1272. http://dx.doi.org/

10.1176/appi.ps.201400140.

Baumeister, R.F., Leary, M.R., 1995. The need to belong: desire for interpersonal attachments as a fundamental human motivation. Psychol. Bull. 117, 497-529.

http:// dx.doi.org/10.1037/0033-2909.117.3.497.

Beals, K.P., Peplau, L.A., Gable, S.L., 2009. Stigma management and well-being: the role of perceived social support, emotional processing, and suppression. Personal. Soc.

Psychol. Bull. 35, 867-879. http://dx.doi.org/10.1177/0146167209334783.

Beatty, D.L., Hall, M.H., Kamarck, T.A., Buysse, D.J., Owens, J.F., Reis, S.E., Matthews,

K.A., 2011. Unfair treatment is associated with poor sleep in African American and

Caucasian adults: Pittsburgh SleepSCORE project. Health Psychol. 30, 351-359.

http://dx.doi.org/10.1037/a0022976.

Beck, A.T., Wright, F.D., Newman, C.F., Liese, B.S., 2011. Cognitive Therapy of

Substance Abuse. Guilford Press, New York.

Birchwood, M., Meaden, A., Trower, P., Gilbert, P., Plaistow, J., 2000. The power and omnipotence of voices: subordination and entrapment by voices and significant others. Psychol. Med. 2, 337-344. http://dx.doi.org/10.1017/s0033291799001828.

Blascovich, J., Mendes, W.B., Hunter, S.B., Lickel, B., Kowai-Bell, N., 2001. Perceiver threat in social interactions with stigmatized others. J. Personal. Soc. Psychol. 80,

253-267. http://dx.doi.org/10.1037/0022-3514.80.2.253.

Bowerman, B.L., O'Connell, R.T., 1990. Linear Statistical Models: An Applied Approach.

Brooks/Cole, New York.

Brohan, E., Slade, M., Clement, S., Thornicroft, G., 2010. Experiences of mental illness stigma, prejudice and discrimination: a review of measures. BMC Health Serv. Res.

10, 1-80. http:// dx.doi.org/10.1186/1472-6963-10-80.

Cohen, S., Wills, T.A., 1985. Stress, social support, and the buffering hypothesis. Psychol.

Bull. 98, 310-357. http://dx.doi.org/10.1037/ /0033-2909.98.2.310. 
Cohen, S., Sherrod, D.R., Clark, M.S., 1986. Social skills and the stress-protective role of social support. J. Personal. Soc. Psychol. 50, 963-973. http://dx.doi.org/10.1037/ 0022-3514.50.5.963.

Cook, D.R., 1987. Measuring shame: the internalized shame scale. Alcohol. Treat. Q. 4, 197-215. http://dx.doi.org/10.1300/j020v04n02_12.

Corrigan, P.W., Penn, D.L., 1999. Lessons from social psychology on discrediting psychiatric stigma. Am. Psychol. 54, 765-776. http:/ / dx.doi.org/10.1037/0003-

066x.54.9.765.

Corrigan, P.W., Watson, A.C., 2002. Understanding the impact of stigma on people with mental illness. World Psychiatry 1, 16-20.

Corrigan, P.W., Watson, A.C., Barr, L., 2006. The self-stigma of mental illness: implications for self-esteem and self-efficacy. J. Soc. Clin. Psychol. 25, 875-884.

http://dx.doi.org/10.1521/jscp.2006.25.8.875.

Crisp, A.H., Gelder, M.G., Rix, S., Meltzer, H.I., Rowlands, O.J., 2000. Stigmatisation of people with mental illnesses. Br. J. Psychiatry 177, 4-7. http://dx.doi.org/10.1192/

bjp.177.1.4.

Cunningham, J.A., Sobell, L.C., Sobell, M.B., Agrawal, S., Toneatto, T., 1993. Barriers to treatment: why alcohol and drug abusers delay or never seek treatment. Addict.

Behav. 18, 347-353. http:/ / dx.doi.org/10.1016/0306-4603(93)90036-9.

Eisenberger, N.I., Lieberman, M.D., Williams, K.D., 2003. Does rejection hurt? An fMRI study of social exclusion. Science 302, 290-292. http:/ / dx.doi.org/10.1037/e633912013-635.

Ellis, B., Bernichon, T., Yu, P., Roberts, T., Herrell, J.M., 2004. Effect of social support on substance abuse relapse in a residential treatment setting for women. Eval. Program.

Plan. 27, 213-221. http:/ / dx.doi.org/10.1016/j.evalprogplan.2004.01.011.

Fazio, R.H., Jackson, J.R., Dunton, B.C., Williams, C.J., 1995. Variability in automatic activation as an unobtrusive measure of racial attitudes: a bona fide pipeline? J. Personal. Soc. Psychol. 69, 1013-1027. http:/ / dx.doi.org/10.1037/0022-3514.69.6.1013.

Fritz, M.S., MacKinnon, D.P., 2007. Required sample size to detect the mediated effect. Psychol. Sci. 18, 233-239.

Gilbert, P., 2000. The relationship of shame, social depression and anxiety: the role of the evaluation of social rank. Clin. Psychol. Psychother. 7, 174-189.

http://dx.doi.org/10.1002/1099-0879(200007)7:3 < 174::aid-cpp236 > 3.0.co;2-u.

Greenwald, A.G., Banaji, M.R., 1995. Implicit social cognition: attitudes, self-esteem, and stereotypes. Psychol. Rev. 102, 4-27. http://dx.doi.org/10.1037/0033-

295X.102.1.4.

Hasson-Ohayon, I., Ehrlich-Ben, Or, S., Vahab, K., Amiaz, R., Wiser, M., Roe, D., 2012.

Insight in mental illness and self-stigma: the mediating role of shame proneness.

Psychiatry Res. 200, 802-806. http://dx.doi.org/10.1016/j.psychres.2012.07.038.

Hayes, A.F., 2013. Introduction to Mediation, Moderation, and Conditional Process

Analysis: A Regression-Based Approach. Guilford Press, New York.

Hayes, S.C., 2004. Acceptance and commitment therapy, relational frame theory, and the third wave of behavioral and cognitive therapies. Behav. Ther. 35, 639-665. http:// dx.doi.org/10.1016/s0005-7894(04)80013-3.

Klingemann, H., Gmel, G., 2001. Mapping the Social Consequences of Alcohol Consumption. Kluwer Academic Publishers, Dordrecht.

Kroenke, K., Spitzer, R., Williams, J., Lowe, B., 2009. An ultra-brief screening scale for depression and anxiety: the PHQ-4. Psychosomatics 50, 613-621.

http://dx.doi.org/10.1176/appi.psy.50.6.613.

LeBel, T.P., 2008. Perceptions of and responses to stigma. Sociol. Compass 2, 409-432. http://dx.doi.org/10.1111/j.1751-9020.2007.00081.x.

Li, L., Lee, S.J., Thammawijaya, P., Jiraphongsa, C., Rotheram-Borus, M.J., 2009. 
Stigma, social support, and depression among people living with HIV in Thailand. AIDS Care 21, 1007-1013. http:/ / dx.doi.org/10.1080/09540120802614358.

Link, B.G., Phelan, J.C., 2013. Labeling and stigma. In: Aneshensel, C.S., Phelan, J.C., Bierman, A. (Eds.), Handbook of the Sociology of Mental Health. Springer, Dordrecht, 525541.

Link, B.G., Yang, L.H., Phelan, J.C., Collins, P.Y., 2004. Measuring mental illness stigma. Schizophr. Bull. 30, 511-541. http:// dx.doi.org/10.1093/oxfordjournals.schbul.a007098. Link, B.G., Cullen, F.T., Struening, E., Shrout, P.E., Dohrenwend, B.P., 1989. A modified labeling theory approach to mental disorders: an empirical assessment. Am. Sociol. Rev. 54, 400-423. http://dx.doi.org/10.2307/2095613.

Link, B.G., Struening, E.L., Rahav, M., Phelan, J.C., Nuttbrock, L., 1997. On stigma and its consequences: Evidence from a longitudinal study of men with dual diagnosis of mental illness and substance abuse. J. Health Soc. Behav. 38, 177-190.

http://dx.doi.org/10.2307/2955424.

Link, B.G., Struening, E.L., Neese-Todd, S., Asmussen, S., Phelan, J.C., 2001. Stigma as a barrier to recovery: the consequences of stigma for the self-esteem of people with mental illness. Psychiatri. Serv. 52, 1621-1626. http://dx.doi.org/10.1176/appi.ps.52.12.1621. Livingston, J.D., Boyd, J.E., 2010. Correlates and consequences of internalized stigma for people living with mental illness: a systematic review and meta-analysis. Soc. Sci.

Med. 71, 2150-2161. http://dx.doi.org/10.1016/j.socscimed.2010.09.030.

Luoma, J.B., Kohlenberg, B.S., Hayes, S.C., Bunting, K., Rye, A.K., 2008. Reducing self-stigma in substance abuse through acceptance and commitment therapy: model, manual development, and pilot outcomes. Addict. Res. Theory 16, 149-165. http:// dx.doi.org/10.1080/16066350701850295.

Luoma, J.B., O'Hair, A., Kohlenberg, B., Hayes, S., Fletcher, L., 2010. The development and psychometric properties of a new measure of perceived stigma toward substance users. Subst. Use Misuse 45, 47-57. http://dx.doi.org/10.3109/10826080902864712.

Luoma, J.B., Twohig, M.P., Waltz, T., Hayes, S.C., Roget, N., Padilla, M., Fisher, G., 2007. An investigation of stigma in individuals receiving treatment for substance abuse. Addict. Behav. 32, 1331-1346. http:// dx.doi.org/10.1016/j.addbeh.2006.09.008.

Major, B., O'Brien, L.T., 2005. The social psychology of stigma. Annu. Rev. Psychol. 56, 393-421. http:// dx.doi.org/10.1146/annurev.psych.56.091103.070137.

Medical Research Council, 2012. Good Research Practice: Principles and Guidelines. MRC, London.

Menard, S., 1995. Applied Logistic Regression Analysis. Sage University Paper Series on Quantitative Applications in Social Sciences (07-106). Sage, Thousand Oaks.

Mickelson, K.D., 2001. Perceived stigma, social support, and depression. Pers. Soc.

Psychol. Bull. 27, 1046-1056. http:// dx.doi.org/10.1177/0146167201278011.

Mueller, B., Nordt, C., Lauber, C., Rueesch, P., Meyer, P.C., Roessler, W., 2006. Social support modifies perceived stigmatization in the first years of mental illness: a longitudinal approach. Soc. Sci. Med. 62, 39-49. http:/ / dx.doi.org/10.1016/

j.socscimed.2005.05.014.

Myers, R.H., 1990. Classical and Modern Regression with Applications. PWS and Kent Publishing Company, Boston.

Nguyen, A.W., Chatters, L.M., Taylor, R.J., Mouzon, D.M., 2016. Social support from family and friends and subjective well-being of older African Americans. J.

Happiness Stud. 17, 959-979. http:/ / dx.doi.org/10.1007/ s10902-015-9626-8.

Page, S., 1996. Effects of the mental illness label in 1993: Acceptance and rejection in the community. J. Health Soc. Policy 7, 61-68. http://dx.doi.org/10.1300/j045v07n02_05. Pallesen, S., Bjorvatn, B., Nordhus, I., Silvertsen, B., Hjornevik, M., Morin, C., 2008. A new scale for measuring insomnia: the Bergen Insomnia Scale 1. Percept. Mot. Skill 
107, 691-706. http://dx.doi.org/10.2466/pms.107.3.691-706.

Parcesepe, A.M., Cabassa, L.J., 2013. Public stigma of mental illness in the United States: a systematic literature review. Adm. Policy Ment. Health 40, 384-399.

http://dx.doi.org/10.1007/s10488-012-0430-z.

Pascoe, E.A., Smart Richman, L., 2009. Perceived discrimination and health: a metaanalytic review. Psychol. Bull. 135, 531-554. http://dx.doi.org/10.1037/a0016059.

Penn, D.L., Martin, J., 1998. The stigma of severe mental illness: some potential solutions for a recalcitrant problem. Psychiatr. Q. 69, 235-247.

http://dx.doi.org/10.1023/a:1022153327316.

Pescosolido, B.A., Monahan, J., Link, B.G., Stueve, A., Kikuzawa, S., 1999. The public's view of the competence, dangerousness, and need for legal coercion of persons with mental health problems. Am. J. Public Health 89, 1339-1345.

http://dx.doi.org/10.2105/ AJPH.89.9.1339.

Preacher, K.J., Hayes, A.F., 2008a. Asymptotic and resampling strategies for assessing and comparing indirect effects in multiple mediator models. Behav. Res. Methods 40, 879-891. http:// dx.doi.org/10.3758/brm.40.3.879.

Preacher, K.J., Hayes, A.F., 2008b. Contemporary approaches to assessing mediation in communication research. In: Hayes, A.F., Slater, M.D., Snyder, L.B. (Eds.), The Sage Sourcebook of Advanced Data Analysis Methods for Communication Research. Sage, Thousand Oaks, 13-54.

Preacher, K.J., Kelley, K., 2011. Effect size measures for mediation models: quantitative strategies for communicating indirect effects. Psychol. Methods 16, 93-115.

http://dx.doi.org/10.1037/a0022658.

Rehm, J., Mathers, C., Popova, S., Thavorncharoensap, M., Teerawattananon, Y., Patra, J., 2009. Global burden of disease and injury and economic cost attributable to alcohol use and alcohol-use disorders. Lancet 373, 2223-2233.

http://dx.doi.org/10.1016/s01406736(09)60746-7.

Ritsher, J.B., Otilingam, P.G., Grajales, M., 2003. Internalized stigma of mental illness: psychometric properties of a new measure. Psychiatry Res. 121, 31-49.

http://dx.doi.org/10.1016/j.psychres.2003.08.008.

Room, R., 2005. Stigma, social inequality and alcohol and drug use. Drug Alcohol Rev. 24, 143-155. http:// dx.doi.org/10.1080/09595230500102434.

Rosenberg, M., 1965. Society and the Adolescent Self-Image. Princeton University Press, Princeton.

Schomerus, G., Corrigan, P.W., Klauer, T., Kuwert, P., Freyberger, H.J., Lucht, M., 2011a. Self-stigma in alcohol dependence: consequences for drinking-refusal selfefficacy. Drug Alcohol Depend. 114, 12-17. http:// dx.doi.org/10.1016/j.drugalcdep.2010.08.013. Schomerus, G., Lucht, M., Holzinger, A., Matschinger, H., Carta, M.G., Angermeyer, M.C., 2011b. The stigma of alcohol dependence compared with other mental disorders: a review of population studies. Alcohol Alcohol. 46, 105-112.

http://dx.doi.org/10.1093/alcalc/agq089.

Semple, S.J., Grant, I., Patterson, T.L., 2005. Utilization of drug treatment programs by methamphetamine users: the role of social stigma. Am. J. Addict. 14, 367-380.

http:// dx.doi.org/10.1080/10550490591006924. Sibitz, I., Amering, M., Unger, A., Seyringer, M.E., Bachmann, A., Schrank, B.,

Woppmann, A., 2011. The impact of the social network, stigma and empowerment on the quality of life in patients with schizophrenia. Eur. Psychiatry 26, 28-33.

http://dx.doi.org/10.1016/j.eurpsy.2010.08.010.

Simbayi, L.C., Kalichman, S., Strebel, A., Cloete, A., Henda, N., Mqeketo, A., 2007. 
Internalized stigma, discrimination, and depression among men and women living with HIV/AIDS in Cape Town, South Africa. Soc. Sci. Med. 64, 1823-1831.

http://dx.doi.org/10.1016/j.socscimed.2007.01.006.

Thoits, P.A., 2011. Mechanisms linking social ties and support to physical and mental health. J. Health Soc. Behav. 52, 145-161. http:/ / dx.doi.org/10.1177/0022146510395592.

Thomas, K.S., Bardwell, W.A., Ancoli-Israel, S., Dimsdale, J.E., 2006. The toll of ethnic discrimination on sleep architecture and fatigue. Health Psychol. 25, 635-642.

http:// dx.doi.org/10.1037/0278-6133.25.5.635.

Uchino, B.N., 2006. Social support and health: a review of physiological processes

potentially underlying links to disease outcomes. J. Behav. Med. 29, 377-387.

http://dx.doi.org/10.1007/s10865-006-9056-5.

Van Boekel, L.C., Brouwers, E.P., Van Weeghel, J., Garretsen, H.F., 2013a. Public opinion on imposing restrictions to people with an alcohol-or drug addiction: a cross-sectional survey.

Soc. Psychiatry Psychiatr. Epidemiol. 48, 2007-2016. http:/ / dx.doi.org/10.1007/s00127-013 0704-0.

Van Boekel, L.C., Brouwers, E.P., Van Weeghel, J., Garretsen, H.F., 2013b. Stigma among health professionals towards patients with substance use disorders and its consequences for healthcare delivery: systematic review. Drug Alcohol Depend. 131, 23-35.

http://dx.doi.org/10.1016/j.drugalcdep.2013.02.018.

Van Boekel, L.C., Brouwers, E.P.M., Van Weeghel, J., Garretsen, H.F.L., 2016.

Experienced and anticipated discrimination reported by individuals in treatment for substance use disorders within the Netherlands. Health Soc. Care Commun. 24, e23-e33. http://dx.doi.org/10.1111/hsc.12279.

Van Brakel, W.H., 2006. Measuring health-related stigma - a literature review. Psychol. Health Med. 11, 307-334. http://dx.doi.org/10.1080/13548500600595160.

Vass, V., Morrison, A.P., Law, H., Dudley, J., Taylor, P., Bennett, K.M., Bentall, R.P., 2015. How stigma impacts on people with psychosis. The mediation effect of selfesteem and hopelessness on subjective recovery and psychotic experiences.

Psychiatry Res. 230, 487-495. http://dx.doi.org/10.1016/j.psychres.2015.09.042.

Vyavaharkar, M., Moneyham, L., Corwin, S., Saunders, R., Annang, L., Tavakoli, A., 2010. Relationships between stigma, social support, and depression in HIV-infected African American women living in the rural Southeastern United States. J. Assoc.

Nurses AIDS Care 21, 144-152. http:/ / dx.doi.org/10.1016/j.jana.2009.07.008.

Wiechelt, S.A., Sales, E., 2001. The role of shame in women's recovery from alcoholism: the impact of childhood sexual abuse. J. Soc. Work Pract. Addict. 1, 101-116.

http://dx.doi.org/10.1300/j160v01n04_07.

Williams, D.R., Mohammed, S.A., 2009. Discrimination and racial disparities in health: evidence and needed research. J. Behav. Med. 32, 20-47. http://dx.doi.org/10.1007/s10865008-9185-0.

Williams, K.D., Zadro, L., 2001. Ostracism: on being ignored, excluded and rejected. In: Leary, M.R. (Ed.), Interpersonal Rejection. Oxford University Press, New York, 21-53.

Wood, L., Irons, C., 2016. Exploring the associations between social rank and external shame with experiences of psychosis. Behav. Cogn. Psychother. 44, 527-538.

http://dx.doi.org/10.1017/S1352465815000570.

World Medical Association, 2013. WMA Declaration of Helsinki - Ethical Principles for Medical Research Involving Human Subjects. World Medical Association, Brazil.

Zadro, L., Williams, K.D., Richardson, R., 2004. How low can you go? Ostracism by a computer is sufficient to lower self-reported levels of belonging, control, self-esteem, and meaningful existence. J. Exp. Soc. Psychol. 40, 560-567.

http://dx.doi.org/10.1016/j.jesp.2003.11.006. 
Zimet, G.D., Dahlem, N.W., Zimet, S.G., Farley, G.K., 1988. The multidimensional scale of perceived social support. J. Personal. Assess. 52, 30-41.

http://dx.doi.org/10.1207/s15327752jpa5201_2. 